\title{
Density and population viability of coastal marten: a rare and geographically isolated small carnivore
}

\author{
Mark A Linnell ${ }^{1}$, Katie Moriarty ${ }^{\text {Corresp., }}{ }^{2}$, David S Green ${ }^{3}$, Taal Levi ${ }^{4}$ \\ 1 Department of Forest Engineering, Resources, and Management, Oregon State University, Corvallis, Oregon, United States \\ 2 Pacific Northwest Research Station, U.S. Department of Agriculture, Forest Service, Olympia, Washington, United States \\ 3 Institute for Natural Resources, Oregon State University, Corvallis, Oregon, United States \\ 4 Department of Fisheries and Wildlife, Oregon State University, Corvallis, Oregon, United States \\ Corresponding Author: Katie Moriarty \\ Email address: ktmoriarty22@gmail.com
}

Pacific martens (Martes caurina) in coastal forests of Oregon and northern California in the United States are rare and geographically isolated, prompting a petition for listing under the Endangered Species Act. If listed, regulations have the potential to influence land-use decisions on public and private lands, but no estimates of population size, density, and viability of remnant marten populations are available for evaluating their conservation status. We used GPS and VHF telemetry and spatial mark-resight to estimate home ranges, density, and population size of Pacific martens in the Oregon Dunes National Recreation Area, central coast Oregon. We then estimated population viability at differing levels of human-caused mortality (e.g., vehicle mortality). Marten home ranges were small on average (females $=0.8 \mathrm{~km}^{2}$, males $1.5 \mathrm{~km}^{2}$ ) and density $\left(1.13\right.$ martens $/ 1 \mathrm{~km}^{2}$ ) was the highest reported for North American populations (M. caurina, M. americana). We estimated 71 adult martens (95\% Credible Interval: 41-87) across two subpopulations separated by a large barrier (Umpqua River). Using population viability analysis, extinction risk for a subpopulation of 30 martens ranged from $34 \%$ to $100 \%$ with two or more annual humancaused mortalities. Absent population expansion, limiting human-caused mortalities will likely have the greatest conservation impact. 
1 Density and population viability of coastal marten: a rare and geographically isolated small

2 carnivore

3 RH: Trajectories of a small isolated marten population

4 Mark A. Linnell ${ }^{1 a}$, Katie M. Moriarty ${ }^{2 a}$, David S. Green ${ }^{3}$, Taal Levi ${ }^{4}$

5

$6 \quad{ }^{1}$ Department of Forest Engineering, Resources, and Management, Oregon State University, 280

7 Peavy Hall, Corvallis, OR 97331, USA

82 Pacific Northwest Research Station, USDA Forest Service, $362593^{\text {rd }}$ Avenue SW, Olympia,

9 WA 98512, USA

$10{ }^{3}$ Institute for Natural Resources, Oregon State University, 234 Strand Agriculture Hall,

11 Corvallis, OR 97331, USA

$12{ }^{4}$ Department of Fisheries and Wildlife, Oregon State University, Corvallis, OR 97331, USA

13 a co-lead authors

14 Corresponding Author:

15 Katie Moriarty

16 Email address: ktmoriarty22@gmail.com

17 


\section{Abstract}

19 Pacific martens (Martes caurina) in coastal forests of Oregon and northern California in the

20 United States are rare and geographically isolated, prompting a petition for listing under the

21 Endangered Species Act. If listed, regulations have the potential to influence land-use decisions

22 on public and private lands, but no estimates of population size, density, and viability of remnant

23 marten populations are available for evaluating their conservation status. We used GPS and VHF

24 telemetry and spatial mark-resight to estimate home ranges, density, and population size of

25 Pacific martens in the Oregon Dunes National Recreation Area, central coast Oregon. We then

26 estimated population viability at differing levels of human-caused mortality (e.g., vehicle

27 mortality). Marten home ranges were small on average (females $=0.8 \mathrm{~km}^{2}$, males $1.5 \mathrm{~km}^{2}$ ) and

28 density (1.13 martens $\left./ 1 \mathrm{~km}^{2}\right)$ was the highest reported for North American populations $(M$.

29 caurina, M. americana). We estimated 71 adult martens (95\% Credible Interval: 41-87) across

30 two subpopulations separated by a large barrier (Umpqua River). Using population viability

31 analysis, extinction risk for a subpopulation of 30 martens ranged from $34 \%$ to $100 \%$ with two or

32 more annual human-caused mortalities. Absent population expansion, limiting human-caused

33 mortalities will likely have the greatest conservation impact. 
36

\section{Introduction}

Conserving wildlife while maintaining economic growth is one of the most pervasive conservation and policy challenges globally. This balance in the United States is enforced in part by the Endangered Species Act (ESA), which can regulate land-use on both public and private lands for the conservation of imperiled species. Forests of the Pacific Northwest of North America highlight challenges between land-use and endangered species conservation as demonstrated by the history with northern spotted owl (Strix occidentalis caurina, Simberloff 1987). Now decades after the conflict over listing the northern spotted owl, a distinct population segment of a forest-dependent small carnivore is a litigation target, petitioned for listing under the ESA (Anonymous 2017).

Pacific martens (Martes caurina) are a small carnivore considered to be a habitat specialist closely associated with structurally complex montane forests with seasonal snow cover in the western United States (Buskirk \& Ruggiero 1994; Zielinski 2013). Coastal populations of Pacific martens in coastal Oregon and California are near the southern edge of their distribution and live in near-coast forests with limited or no snow cover. Recent extensive distributional surveys suggest two or three potential populations in coastal Oregon and northern California (Moriarty et al. 2016a; Zielinski et al. 2001). These coastal populations of martens have contracted in the $20^{\text {th }}$ century (Zielinski et al. 2001), prompting petitions to list a Distinct Population Segment, often referred to as Humboldt marten (Martes caurina humboldtensis), as threatened or endangered (Center for Biological Diversity 2010). The northernmost population is located in the central Oregon coast (Moriarty et al. 2016a), and it is also the most isolated (i.e., > $60 \mathrm{~km}$ from the nearest adjacent population). 
The U.S. Fish and Wildlife Service determined that the coastal Distinct Population

59 Segment of the Pacific martens in California and Oregon did not warrant listing as a threatened

60 or endangered species under the Endangered Species Act in 2015 (US Fish Wildlife Service

61 2015). The finding by the U.S. Fish and Wildlife Service, however, included assumptions that

62 coastal martens were abundant in central Oregon from speculation that the relatively high

63 number of road-killed individuals there in the past three decades ( $n=14$, Zielinski et al. 2001, p.

64 487) and extensive Late-Seral Reserves on federal lands provided habitat for these martens

65 (Slauson 2015). Recent distributional surveys indicated this population likely occupies a $<500 \mathrm{~m}$

66 wide band of young (i.e., $<70$ years old) forests growing on sand dunes along the margin of the

67 Pacific Ocean west of Highway 101 and no evidence of martens $>3 \mathrm{~km}$ inland (Fig. 1, Moriarty

68 et al. 2016a). Very little is known about population size, or spatial ecology of martens living in

69 the central Oregon coast.

70 Our objectives were to describe marten density, population size, and population viability

71 in the central Oregon coast. Specifically, we used spatial mark-resight (SMR) models to evaluate

72 density in a portion of our study area and then we applied our density estimate to coastal forests

73 west of Highway 101 where martens resided to estimate total population size. We assumed that,

74 1) forest characteristics were similar across our study area, and 2) because martens are highly

75 territorial, density would be static across study areas if home range sizes were similar between

76 individuals. We then used a population viability analysis to quantify the potential effects of

77 human-caused mortality (i.e., legal trapping, vehicle strikes). Finally, because density and home

78 range size are often correlated with foraging resources (Kittle et al. 2015; Mattisson et al. 2016),

79 we compared density and home range sizes of martens in coastal Oregon to other North 
80 American populations (Martes caurina, Martes americana) to infer year-round food resource

81 availability compared to other studies.

\section{Methods}

\section{Study area}

We surveyed the northernmost population of coastal martens along the central Oregon coast within the $125 \mathrm{~km}^{2}$ Oregon Dunes National Recreation Area (hereafter, "Oregon Dunes"). Coastal forests within the Oregon Dunes consisted of a narrow north-south strip along the margin of the Pacific Ocean bounded by two large rivers to the north and south (i.e., Siuslaw and Coos Rivers), Highway 101 to the east, and bisected by the Umpqua River, which is $600-\mathrm{m}$ wide at the confluence with the Pacific Ocean (Fig. 1). Much of the forested area was the result of recent expansion over the last 70 years coincident with stabilization of near-coast beaches by European beach grass (Amophila arenaria) into mounded fore dunes, which limited sand deposition and facilitated vegetation expansion into previously shifting open sand (Christy et al. 1998). trees (Picea sitchensis). The sub-tree canopy was dense, extended to $>2.5 \mathrm{~m}$ in height, and it was dominated by willow (Salix hookeri), Pacific waxmyrtle (Myrica californica), salal

97 (Gaultheria shallon), and slough sedge (Carex obnupta) on seasonally flooded sites, and berry98 producing ericaceous shrubs (e.g., evergreen huckleberry (Vaccinium ovatum), salal) on

99 seasonally dry sites (Christy et al. 1998). Coastal forests differed substantially from inland 100 forests east of Highway 101 in vegetation age, structure, composition, and their vertebrate 101 communities (Eriksson 2016). Inland forests were a mix of young (i.e., 0-80 years) and mature 102 (i.e., >80 years old) Douglas-fir (Pseudotsuga menziesii) and Sitka spruce forests. Mature forests 
103 on federal lands were primarily managed as Late Seral Reserves to protect habitat for northern

104 spotted owls (Strix occidentalis) and marbled murrelets (Brachyramphus marmoratus, Davis et

105 al. 2015). Forests in the Oregon Dunes supported a high diversity of vertebrates, including

106 several predators and competitors of martens (e.g., gray foxes Urocyon cinereoargenteus,

107 coyotes Canis latrans, cougars Puma concolor; Eriksson 2016; Eriksson et al. in review).

108 To distinguish vegetation cover (i.e., forests and tall shrubs) from open sand, we used

109 airborne light detection and ranging data collected at 1-m resolution. We defined vegetation

110 cover as $>40 \%$ cover of pixels $>1 \mathrm{~m}$ in height within a $100-\mathrm{m}$ circular radius moving window of

111 each pixel. This process produced a raster layer that smoothed small gaps in vegetation cover

112 (i.e., sand gaps $<30 \mathrm{~m}$ ) that martens could presumably move through, but that excluded broad

113 expanses of open sand that we assumed represented non-habitat for martens, particularly because

114 of the presence of predators (Moriarty et al. 2015). The northern (i.e., north of Umpqua River,

115 Fig. 1b) and southern (i.e., south of Umpqua River, Fig. 1c) study areas were comprised of 36.9

$116 \mathrm{~km}^{2}$ and $25.6 \mathrm{~km}^{2}$ of vegetation cover, respectively.

117 Minimum and maximum temperatures in July and January were $10.1^{\circ} \mathrm{C}$ and $20.3^{\circ} \mathrm{C}$ and

$1183.2^{\circ} \mathrm{C}$ and $10.2^{\circ} \mathrm{C}$, respectively. Annual precipitation averaged $176 \mathrm{~cm}$, and occurred primarily

119 between November and March (Western Regional Climate Center 1971-2016). Elevation within

120 the study area ranged from eight to $80 \mathrm{~m}$.

121 Live-capture and home range size estimates

122 We live-trapped and radio-marked Pacific martens from October to December 2015 using

123 traps spaced approximately $1 \mathrm{~km}$ apart with some additional clustering of traps at $<1 \mathrm{~km}$ (Fig. 1)

124 using methods described in Moriarty et al. (2017) and Mortenson \& Moriarty (2015). We fit

125 adult martens (i.e., > two years old) with a VHF (Advanced Telemetry Systems, Minnesota, 
126 USA; 29 g) or GPS/VHF collar (Quantum 4000 Micro-Mini GPS collars, Telemetry Solutions,

127 California, USA; 41-44 g; or G10 snap technology GPS, Advanced Telemetry Systems,

128 Minnesota, USA; $27 \mathrm{~g}$; Table S1). Each individual marten was marked with a unique pattern of

129 reflective tape attached to the antenna of the radio collar, which we used to resight marked

130 individuals using black-LED remote cameras (Aggressors, 2015, Bushnell, Missouri, USA; Fig.

131 2). All capture and handling procedures were approved by the USDA Forest Service's Institute

132 for Animal Care and Use Committee (USFS 2015-002) under an Oregon Department of Fish and

133 Wildlife Scientific Take Permit (ODFW 119-15). We removed collars in January and February

1342016.

135 We programmed GPS collars to collect locations separated by 5 min, and only included

136 locations in our analyses with predicted errors $<30 \mathrm{~m}$ and time periods where data were

137 collected for $>72$ consecutive hrs (details in Moriarty et al. 2017). We located individuals with

138 VHF-only collars at least twice per week. We only used VHF locations where the variance of $\mathrm{x}$

139 and y was $<400 \mathrm{~m}$ determined with Location of a Signal (Ecological Software Solutions LLC).

140 We estimated $99 \%$ local convex hull home ranges, discarding $1 \%$ of the furthest dispersed

141 locations (Lyons et al. 2013), using the t-LoCoH package in R. Local convex hulls were

142 constructed using 35 neighboring locations $(k=35)$, regardless of time between locations $(s=0$;

143 Lyons et al. 2013; R Core Team 2013). These parameterizations best reflected marten space use

144 in our study (Moriarty et al. 2017) by limiting the formation of multiple activity centers, and they

145 providing a smoothed outer contour boundary.

\section{Spatial mark-resight}

147 We deployed 31 remote camera stations for 39 nights in December 2015 and early

148 January 2016 along a linear transect (henceforth, "SMR transect") that overlapped the area 
149 occupied by radio-tracked martens in the northern study area (Fig. 3). We set remote cameras

150 (Bushnell Aggressor, model: 119776; Bushnell Corporation, Overland Park, KS) two to three m

151 from bait and we programmed them to record one photo after motion was detected with a one-

152 second lag between consecutive photos. Each station included an olfactory lure (Gusto,

153 Minnesota Trapline Products, Pennacock, MN) and baits that were checked and replaced weekly.

154 We placed bait, in the form of $\sim 250 \mathrm{~g}$ of chicken and $\sim 100 \mathrm{~g}$ of strawberry jam, at each camera

155 during setup and replaced it at each site on 3 visits. Camera stations were distributed $311 \pm 91 \mathrm{~m}$

156 (mean \pm 1 standard deviation) apart within vegetation cover with a minimum goal of four camera

157 stations accessible to each female (Sun et al. 2014). Visits occurred every $8.2 \pm 1.5$ days after 158 setup.

159 We estimated the density of martens from our photographic data using a generalized 160 spatial mark-resight model (Whittington et al. 2018; Code in Article S1). Generalized spatial

161 mark-resight models combine the latent processes that generate both the capture (i.e., marking)

162 and resight data (i.e., cameras) to estimate the number of latent activity centers $\left(s_{i}\right)$ within the

163 study area (Whittington et al. 2018). We defined our study area as a discrete state-space $S$ of a

164 100-m grid within a 5-km buffer around camera stations, excluding cells in the Pacific Ocean.

165 We defined live-capture data as the binomially distributed random variable $y c a p_{i j}$

166 representing the number of times that marten $I$ was captured in $\operatorname{trap} j$ as a function of the

167 probability of capture $\left(\right.$ pcap $\left._{i j}\right)$ and the number of nights that trap $j$ was open $\left(K_{t r a p}\right)$ :

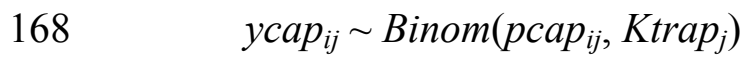

169 We hypothesized that the probability of capture would vary by sex and the distance between the

170 location of trap $j$ and the activity center of marten $i$ :

171

$$
\operatorname{pcap}_{i j}=p 0 \operatorname{cap}_{i} \times e^{\left(-d_{i j}^{2} / 2 \mathrm{if}_{k}^{2}\right)}
$$


172 where the average probability of capture $p 0 c a p_{i}$ was modeled as a function of the sex of each

173 marten $\left(\operatorname{logit}\left(p 0 c a p_{i}\right)=\beta_{0}+\beta_{1} \times \operatorname{sex}_{i}\right)$, a half-normal decay function where $d_{i j}$ is the distance

174 between the trap and the latent activity center of individual $i\left(s_{i}\right)$, and the standard deviation of a

175 bivariate normal distribution reflecting space-use varying by $\operatorname{sex}\left(\sigma_{k}\right)$. We parameterized $\sigma$

176 separately for each sex (See Article S1).

177 We defined camera resighting data as the Bernoulli distributed random variable $y_{c a m}{ }_{i j k}$

178 representing whether or not the previously live-captured marten $i$ was resighted at camera station

$179 j$ on night $k$ as:

$180 \quad \operatorname{ycam}_{i j k} \sim \operatorname{Bern}\left(\right.$ pcam $\left._{i j k}\right)$

181 where pcam $_{i j k}$ is a function describing the average daily rate of detecting martens on camera.

182 Similar to the capture data, we hypothesized that the average daily rate of detection would vary

183 by sex and the distance between the station and their latent activity center $\left(\right.$ pcam $_{i j k}=p_{0 c a m_{i j k}} \times$

$\left.184 e^{\left(-d_{i j}^{2} / 2 \mathrm{If}_{k}^{2}\right)}\right)$. We also hypothesized that the time since bait addition would influence the rate of

185 detecting martens on camera, so we added a variable to test the effect of days since baiting on the

186 average rate of detection $\left(\operatorname{logit}\left(p_{0 c a m}\right)=\delta_{0}+\delta_{1} \times \operatorname{sex}_{i}+\delta_{2} \times \operatorname{days}_{j k}\right)$.

187 We modeled activity center locations using a non-homogeneous Poisson point process in

$188 S$ to examine whether locations of marten activity centers in the Oregon Dunes were associated

189 with percent vegetation cover. We calculated the percent vegetation cover in each grid cell $g$ in

$190 S$, and used an intensity function to model the location of activity centers as:

$$
\mu_{g}=\operatorname{area}_{g} \tilde{\mathrm{A}}-e^{a_{0}+a_{1} \tilde{\mathrm{A}}-\text { vegetation coverforest cover }} g+a_{2} \tilde{\mathrm{A}}-\text { forest cover }_{g}^{2}
$$

192 where the predicted number of activity centers in grid cell $g\left(\mu_{g}\right)$ is a function of an intercept

$193\left(\alpha_{0}\right)$, the linear effect of vegetation cover $\left(\alpha_{1}\right)$, and the size of the grid cell $\left(\right.$ area $\left._{g} ; 0.01 \mathrm{~km}^{2}\right)$. We

194 incorporated telemetry data to increase the precision of our estimates for the movement 
195 parameters and the location of marten activity centers (Royle et al. 2013; Sollmann et al. 2013).

196 Telemetry locations of martens were modeled as being generated from the normally distributed

197 random variable with a mean of $s_{i}$ and a precision of $1 / \mathrm{If}_{k}^{2}($ See Article S1). Martens can travel to

198 any point in their home range within one hr (Moriarty et al. 2016b; Moriarty et al. 2017).

199 Accordingly, we only used locations that were at least one hr apart to ensure independence of 200 telemetry locations (Sollmann et al. 2013).

201 We followed Whittington et al. (2018) in their treatment of the sightings of unmarked 202 individuals; the number of unmarked individuals detected at camera station $j$ on night $k\left(\mathrm{nU}_{j k}\right)$ 203 was modeled as:

204

205

where the number of sightings of unmarked individuals was modeled to be generated

207 from a latent Bernoulli process of resight probability $\left(\mathrm{yu}_{i j k} \sim \operatorname{Bern}\left(\right.\right.$ pcam $\left._{i j k}\right)$, based on the same 208 probabilities of resighting as defined previously $\left(\right.$ pcam $\left._{i j k}\right)$. Similar to the sightings of marked 209 individuals, we assumed that a detection of an unmarked individual at our cameras on a day

210 arose from a Bernoulli process. Unmarked individuals were seen infrequently on our cameras

211 ( $\mathrm{n}=14$ sightings throughout the duration of the study), and identified as being present at the

212 camera for a single bout typically $<19$ minutes. Thus, it was highly unlikely that more than 1

213 unmarked individual was captured on our cameras per day. The code for our SMR model can be 214 found in Supplemental Article S1.

215 We fit our models using data augmentation (Royle \& Dorazio 2008; Royle \& Young 216 2008) and the Markov-Chain Monte Carlo (MCMC) methods of JAGS (Plummer 2003) with the 217 jagsUI package (Kellner 2014) in R v. 3.2.3 (R Core Team 2016). We used uninformative prior 
218 distributions for all parameters (See Article S1). We calculated estimates from 3,000 MCMC

219 samples, taken from three chains run for 10,000 iterations, thinned by five, following a burn-in

220 of 5,000. We assessed model convergence by examining trace plots and $\hat{R}$ values for parameter

221 estimates (Gelman \& Hill 2007; Gelman et al. 2013). All $\hat{R}$ values were $<1.1$, indicating chain

222 convergence. We estimated the density of martens in our northern study area by determining the

223 number of martens with estimated activity centers located in vegetation cover in the state-space,

224 excluding open sand.

225 To evaluate our assumption that home range sizes were similar, we compared home range

226 sizes in the northern and southern study areas using a general linear model with two parameters:

227 sex and study area. We interpreted test statistics from this model and lacking any significant

228 differences, we assumed density could be extrapolated to estimate population sizes (Moriarty et

229 al. 2017).

230 Population viability

231 We assessed the risk of extirpation for a marten subpopulation over the next 40 years in

232 the context of threats from human activities (e.g., trapping, roadkill; Gerber et al. 2004). We

233 estimated the maximum intrinsic population growth rate using a modified Euler-Lotka equation

234 proposed by Skalski et al. (2008)

235

$$
e^{r a}-e^{-M}\left(e^{r}\right)^{a-1}-m l_{a}=0,
$$

236 where $r$ is the maximum intrinsic growth rate, $a$ is the age at first birth, $m$ is the fecundity

237 constant (number of female offspring/female/year), $e^{-M}$ is the probability of survival, and $l_{a}$ is

238 the probability of survival to maturity. We obtained a range of parameter estimates associated

239 with the maximum reproductive output of two closely related species of North American martens

240 (Martes americana, Martes caurina) in wild populations from the literature (Table 1). Estimates 
241 of $r$ are sensitive to uncertainty in annual survival, $e^{-M}$; we estimated maximum intrinsic growth

242 rateI) assuming average, high, and very high survival rates $(0.7,0.8,0.9$ respectively, McCann et

243 al. 2010) to obtain three values of $r=0.143,0.205,0.268$ (Table 2 ). We used the intermediate

244 value of $r=0.205$ in our population projections, but we also implemented a stochastic element

245 with If $=0.06$ such that the low and high estimates of $r$ would bracket one standard deviation

246 from the mean.

247 We simulated the dynamics of a population beginning at carrying capacity using initial

248 values of the population size $(K)$ equal to 20,30 , and 40 to illustrate how estimates of extirpation

249 risk depend on our uncertainty about the current population size, assuming that immigration

250 between the northern and southern study areas was infrequent due to a large barrier (i.e.,

251 Umpqua River; see population estimates in Results). The density-dependent population dynamics

252 are given by the discrete theta-logistic model with an annual mortality component:

253

$$
N_{t+1}=e^{r\left(1-\left(\frac{N}{K}\right)^{\hat{I}}\right)+\hat{I} \mu}-H_{t},
$$

254 where $\hat{\mathrm{I}} \mu \sim N(0, \mathrm{I} f)$, with $\ddot{\mathrm{I} f}=0.06$ based on the variation in our best estimate of $r$ (Table 2$)$, and

255 mortalities resulting from trapping and road-kills as $H_{t} \sim \operatorname{Pois}(\hat{\mathrm{I}} \gg)$. The rate parameter of the

256 Poisson distribution, Î̀, defines both the mean and variance of the annual mortality through

257 road-kills or trapping $\left(H_{t}\right)$, which takes values of $\hat{I} »=1,2$, or 3 martens in our models $(36$

258 martens harvested 1969-1995, 0-4/year; Verts \& Carraway 1998). We assumed a small density-

259 independent harvest to illustrate how extirpation risk can be influenced by relatively low

260 mortality rates. We conservatively assumed a standard logistic population growth $\left(\hat{\mathrm{I}}_{s}=1\right)$, but we

261 also assumed that density-dependent declines in per-capita growth occurred at higher population

262 densities $\left(\hat{\mathrm{I}}_{s}=2\right)$, which is expected for long-lived mammals (Boyce 1992). We simulated 1,000 
263 population trajectories for each of three initial conditions $(K=20,30$, and 40$)$, three stochastic

264 human-caused mortality rates ( $\hat{\mathrm{I}} \gg=1,2$, and 3 ), and two values of the strength of density

265 dependence using theta $\left(\hat{I}_{s}=1,2\right)$. Finally, we report observed mortalities during our study

266 period. Where appropriate, we report results as mean \pm 1 standard deviation.

\section{Results}

We live-captured and radio-collared six female (three VHF-only, three GPS/VHF) and

four male martens. Our GPS collars collected $1139(\bar{x}$, range: 173-2960) locations over $15.7(\bar{x}$, range: 4-44) days on 8 individuals (4 males, 4 females), and we collected 35 ( $\bar{x}$, range: $23-37)$ locations over 75 ( $\bar{x}$, range: $42-90)$ days for three females with VHF-only collars (Table S1).

272 Home range sizes in our study areas were similar $(t=0.5, p=0.68)$ for males: 1.7, 2.2 (northern, $273 n=2$ ) vs 1.0, 2.2 (southern, $n=2)$, and females $0.59-0.84(\bar{x}=0.67$, northern, $n=4)$ vs 0.71 ,

2740.79 (southern, $n=2$ ). Martens were primarily located in areas of high vegetation cover and 275 vegetation cover within a 100 m moving window of telemetry locations averaged $75 \%(25-75 \%$ 276 quantile range $=60-96 \%, n=11$ martens; Table S1, Fig. S1). Home range sizes were smaller 277 and density was higher in coastal Oregon compared to other North American populations (Fig. 3, 278 Table S2). Across populations, home range sizes were negatively correlated with density (Fig. $2793)$.

280 Density and population size

We incorporated $79.3 \pm 59.2$ telemetry locations per individual into our SMR models. No

282 marked individuals of the same sex were observed visiting the same camera station, and $1.1(\bar{x}$, 283 range: $0.7-1.9) \mathrm{km}$ and 4.7,2.1 $(n=2) \mathrm{km}$ was the furthest distance between camera station 284 detections for females and males, respectively (Fig. 4). 
We estimated marten density as (mean \pm 1 standard deviation) $1.13 \pm 0.15$

286

287 288 289 290 291 292 293 294 295 296 297 298 299 300 301 302 303 304 305 306 307 individuals $/ \mathrm{km}^{2}(95 \%$ Credible Interval $(\mathrm{CrI})=0.81-1.39)$, or $9.75 \pm 1.32$ individuals within the SMR area. Assuming density was constant within vegetation in the $62.5 \mathrm{~km}^{2}$ Oregon Dunes, we estimated a median population size of $42(\mathrm{CrI}=30-51)$ north of the Umpqua River and $29(\mathrm{CrI}=$ 21-36) south of it. Sex did not have a significant effect on the probability of live-capture (Table 3), but female martens had a higher resight probability than males (Table 3). Days since baiting had a significant effect on resight probability; martens were more likely to visit baited cameras closer to a baiting event (Table 3). Percent vegetation cover had a significant effect on the distribution of activity centers (Table 3 ).

\section{Population viability}

We estimated that two or more annual human-caused mortalities on martens (e.g. trapping and road-kills) would lead to a substantial risk of extirpation, particularly at smaller population sizes (Figs. 5,6) and for $\hat{\mathrm{I}}_{s}=1$ (Fig. 5) relative to $\hat{\mathrm{I}}_{s}=2$ (Fig. 6). The likelihood of extirpation when $\hat{I}_{s}=1$ for a population of 30 individuals, which approximated the average of our estimates for each study area, was 32\% and 99\% with two and three annual mortalities, respectively. The probabilities decreased to $1 \%$ and $60 \%$ when $\hat{\mathrm{I}}_{s}=2$ with two and three annual mortalities, respectively. The probability of extirpation increased to $89-100 \%$ and $65-100 \%$ for a population of 20 individuals with two or three annual mortalities.

\section{Discussion}

Our population assessment revealed that the central Oregon population of coastal martens likely has fewer than 87 adults divided into two subpopulations separated by a riverine barrier. Further, this population appears completely isolated with a lack of connectivity to the southern Oregon population. Based on the small population sizes of these subpopulations, our population 
308 projections suggest that even a small amount of human-caused mortalities will strongly increase

309 the likelihood of extirpation over the next 30 years. Further, our analysis is likely an optimistic

310 scenario for marten population viability because we assumed that marten populations would

311 exhibit very high survival and fecundity at low population densities, which may not be the case.

312 Despite these favorable assumptions, marten population viability was low given modest

313 mortality estimates averaging 2-3 individuals annually, even when assuming higher than

314 observed carrying capacities and assuming later onset of density dependence ( $\theta=2$; Fig. 6$)$.

315 Moreover, we did not fully consider environmental stochasticity in our viability analysis. In

316 particular, the extant central Oregon marten population is in a tsunami zone within the Cascadia

317 subduction zone. The probability of a large earthquake and tsunami eliminating much of

318 Oregon's near-coastal forests in the next 50 years is placed at 15 to $20 \%$ (Goldfinger et al. 2012).

319 Such an event would be expected to eliminate much of the forested habitat that the central coast

320 marten population occupies.

321 Martens can be common in structurally complex high elevation montane forests with

322 seasonal snow cover, but they are apparently rare and geographically isolated in coastal Oregon.

323 Nonetheless, the Oregon dunes appeared to provide favorable ecological conditions, and

324 supported the smallest home ranges and highest reported density of martens in North America

325 (Fig. 3). North American martens inhabiting forests with seasonal snow-cover typically consume

326 a narrow range of prey, especially during winter months (Martin 1994), which can lead to

327 substantial inter- and intra-annual variation in food availability (Poole and Graf 1996), and

328 presumably requires martens to defend large amounts of space within their home ranges to meet

329 nutritional requirements. In contrast, low-latitude coastal populations have a broad diet including

330 foods such as late-season berries and over-wintering passerine birds, unavailable to montane and 
331 high latitude martens, particularly during winter (Nagorsen et al. 1989) potentially facilitating the

332 small home ranges observed in our study.

333 Despite the adjacent high-density marten population, the mature forest east of the Oregon

334 Dunes does not support a marten population. The reason for near complete marten absence to the

335 east is unclear. We hypothesize that abundant berry-producing shrubs in the Oregon Dunes

336 directly provide abundant food for martens, and indirectly support marten by increasing the

337 abundance of frugivorous vertebrate prey. Moreover, dense understory vegetation likely

338 mediates interactions with competitors and predators, and provided spaces to hunt and avoid

339 predators similar to snow in winter (Andruskiw et al. 2008). Whether prey availability, habitat-

340 mediated competition, or some combination of these factors limits martens from the extensive

341 inland forests is largely unknown; these questions are key to address when considering the

342 potential for population expansion.

343 In addition to vegetation structure and predation, harvest by humans can affect marten

344 populations. It is currently legal to harvest marten throughout Oregon, including within this

345 small, remnant, coastal population. Marten populations can be resilient to fur harvest when they

346 are abundant, and if breeding females are harvested infrequently compared to males, particularly

347 juvenile males (Robitaille 2017, Banci \& Proulx 1999). Adult females in our study were

348 observed more frequently than adult males at ratios of 1.5:1 (live-trapping) and 3:1 (SMR). Our

349 results were atypical of ratios observed in other marten research studies and in harvested

350 populations; these studies typically demonstrate higher male to female ratios (e.g., McCann et al.

351 2010; Payer \& Harrison 1999; Robitaille 2017). Intolerance among same-sex individuals

352 resulting in intrasexual territoriality typical of martens (Moriarty et al. 2017; Powell 1994) may

353 require juveniles to disperse outside of the Oregon Dunes, especially if the long, narrow forested 
354 habitat resulted in elevated encounter rates between juveniles and resident adults. Alternatively,

355 we spaced live-traps at a relatively fine-scale in our study compared to other studies which may

356 have resulted in higher trap encounter rates by females. Regardless of the mechanism, resident

357 breeding females appear to be vulnerable to live-trapping in the Oregon dunes. Further, of the

358 four vehicle killed mortalities since 2015, three were adult females. Based on our data, a prudent

359 consideration could limit fur harvest to areas outside of the Oregon coast range, reducing the

360 immediate risk of short-term marten extirpation.

361 We have provided a baseline estimate of population size that can be compared to future

362 surveys, allowing the monitoring of population status and viability. Such additional monitoring

363 efforts would inform whether these populations are declining or merely small (Caughley 1994).

364 Small population size, consistent annual human-caused mortality, and isolation indicate this

365 coastal marten population is likely to remain vulnerable to extirpation.

366

367 Acknowledgements

368 We received considerable aid with field logistics, vehicles, housing, and equipment from the

369 Central Coast Ranger District, Siuslaw National Forest. Adam Kotaich contributed significantly

370 to the field work, we also thank Cindy Burns, Crystal Mullins, and Deanna Williams for quickly

371 using field data for management-related discussions and the team that has incorporated martens

372 into the updated Oregon Dunes Restoration Strategy.

373

374 References

375 Andruskiw M, Fryxell JM, Thompson ID, and Baker JA. 2008. Habitat-mediated variation in

376 predation risk in the American marten. Ecology 89:2273-2280. 
377 Anonymous. 2017. Center for Biological Diversity et al., v U.S. Fish and Wildlife Service, et al.

378 Case 15-cv-05754-JST: United States District Court, Northern District of California. $p$

37917.

380 Aune KE, and Schladweiler P. 1997. Age, sex structure, and fecundity of the American marten in

381 Montana. In: Proulx G, Bryant HN, and Woodard PM, eds. Martes: taxonomy, ecology,

382 techniques, and management. Edmonton, Alberta, Canada: Provincial Museum of

383 Alberta, 61-77.

384 Banci, V, and Proulx G. 1999. Resiliency of furbearers to trapping in Canada. In Proulx G, ed,

385 Mammal trapping, Sherwood Park, Alberta: Alpha Wildlife Publications, 175-203

386 Boyce MS. 1992. Population viability analysis. Annual Review of Ecology and Systematics

$387 \quad 23: 481-497$.

388 Buskirk SW, and Ruggiero LF. 1994. American marten. In: Ruggiero LF, Aubry KB, Buskirk

389 SW, Lyon LJ, and Zielinski WJ, eds. The scientific basis for conserving forest

390 carnivores: American marten, fisher, lynx, and wolverine in the western United States.

391 Fort Collins, CO, USA: U.S. Department of Agriculture, Rocky Mountain Research

392 Station, 7-30.

393 Caughley G. 1994. Directions in conservation biology. Journal of Animal Ecology 63:215-244.

394 Center for Biological Diversity. 2010. Petition to list the Humboldt Marten (Martes americana

395 humboldtensis) as Threatened or Endangered under the Federal Endangered Species Act.

396 Submitted to U.S. Department of the Interior on 28 September 2010.

397 Christy JA, Kagan JS, and Wiedemann AM. 1998. Plant associations of the Oregon Dunes

398 National Recreation Area: Siuslaw National Forest, Oregon. U.S. Forest Service, Pacific

$399 \quad$ Northwest Region. p 1-189. 
400 Davis R, Ohmann J, Kennedy R, Cohen W, Gregory M, Yang Z, Roberts H, Gray A, and Spies

401 T. 2015. Northwest Forest Plan - the first 20 years (1994-2013): status and trends of late-

402 successional and old-growth forests USDA Forest Service: Portland, OR, USA.

403 Eriksson C. 2016. Martens in a novel habitat - the importance of prey and habitat structure M. S. 404 thesis M. S. thesis. Lund University.

405 Flynn RW, and Schumacher TV. 2016. Habitat selection of American martens on northeast 406 Chichagof Island, southeast Alaska, 1991-1997. Juneau, Alaska, USA. Wildlife Research Report ADF\&G/DWC/WRR-2016-6: Alaska Department of Fish and Game. p 25.

408

409

410

411

412

414

415

416

417

418

419 420

421

422

Gerber LR, Buenau KE, and Vanblaricom G. 2004. Density dependence and risk of extinction in a small population of sea otters. Biodiversity and Conservation 13:2741-2757.

Godbout G, and Ouellet J-P. 2010. Fine-scale habitat selection of American marten at the southern fringe of the boreal forest. Ecoscience 17:175-185.

Goldfinger C, Nelson CH, Morey JE, Johnson JC, Gutiérrez-Pastor J, Eriksson AT, Gràcia E, Dunhill G, Enkin RJ, Dallimore A, and Villier T. 2012. Turbidite event historyMethods and implications for Holocene paleoseismicity of the Cascadia subduction zone. US Geological Survey, Professional Paper 1661-F:64.

Johnson CA, Fryxell JM, Thompson ID, and Baker JA. 2009. Mortality risk increases with natal dispersal distance in American martens. Proceedings of the Royal Society 276:33613367.

Kellner K. 2014. jagsUI: Run JAGS (specifically, libjags) from R; an alternative user interface for rjags. $R$ package version 1:356-364.

Kittle AM, Anderson M, Avgar T, Baker JA, Brown GS, Hagens J, Iwachewski E, Moffatt S, Mosser A, Patterson BR, Reid DEB, Rodgers AR, Shuter J, Street GM, Thompson ID, 
423

424

425

426

427

428

429

430

431

432

433

434

435

436

437

438

439

440

441

442

443

444

Vander Vennen LM, and Fryxell JM. 2015. Wolves adapt territory size, not pack size to local habitat quality. Journal of Animal Ecology 84:1177-1186. 10.1111/13652656.12366

Lyons AJ, Turner WC, and Getz WM. 2013. Home range plus: a space-time characterization of movement over real landscapes. Movement Ecology 1:1-14.

Martin SK. 1994. Feeding ecology of American martens and fishers. In: Buskirk SW, Harestad AS, Raphael MG, and Powell RA, eds. Martens, sables, and fishers: biology and conservation. Ithica, New York: Cornell University Press, 297-315.

Mattisson J, Rauset GR, Odden J, Andrén H, Linnell JDC, and Persson J. 2016. Predation or scavenging? Prey body condition influences decision-making in a facultative predator, the wolverine. Ecosphere 7:e01407 01410.01002/ecs01402.01407. 10.1002/ecs2.1407

McCann NP, Zollner PA, and Gilbert JH. 2010. Survival of adult martens in northern Wisconsin. Journal of Wildlife Management 74:1502-1507. 10.2193/2009-297

Mead RA. 1994. Reproduction in Martes. In: Buskirk SW, Harestad AS, Raphael MG, and Powell RA, eds. Martens, sables, and fishers: biology and conservation. Ithaca, New York, USA: Cornell University Press, 404-422.

Moriarty KM, Bailey JD, Smythe SE, and Verschuyl J. 2016a. Distribution of Pacific marten in coastal Oregon. Northwestern Naturalist 97:71-81. 10.1898/NWN16-01.1

Moriarty KM, Epps CW, Betts MG, Hance DJ, Bailey JD, and Zielinski WJ. 2015. Experimental evidence that simplified forest structure interacts with snow cover to influence functional connectivity for Pacific martens. Landscape Ecology 30:1865-1877. 10.1007/s10980015-0216-2 
445 Moriarty KM, Epps CW, and Zielinski WJ. 2016b. Forest thinning for fuel reduction changes

446 movement patterns and habitat use by Pacific marten. The Journal of Wildlife

447 Management 80:621-633. 10.1002/jwmg.1060

448

449

450

451

452

453

454

455

456

457

458

459

460

461

462

463

464

465

466

467

Moriarty KM, Linnell MA, Chasco B, Epps CW, and Zielinski WJ. 2017. Using high-resolution short-term location data to describe territoriality in Pacific martens. Journal of Mammalogy 98:679-689.

Mortenson JA, and Moriarty KM. 2015. Ketamine and midazolam anesthesia in Pacific martens (Martes caurina). Journal of Wildlife Disease 51:250-254.

Nagorsen DW, Morrison KF, and Forsberg JE. 1989. Winter diet of Vancouver Island marten (Martes americana). Canadian Journal of Zoology 67:1394-1400. 10.1139/z89-198

Payer DC, and Harrison DJ. 1999. Influence of timber harvesting and trapping on habitat selection and demographic characteristics of marten. Final contract report to Maine Department of Inland Fisheries and Wildlife.: University of Maine, Orono, Maine, USA. $<$ http://library.umaine.edu/cfru/pubs/CFRU281.pdf>. Accessed 17 Feb 2011.

Plummer M. 2003. JAGS: A program for analysis of Bayesian graphical models using Gibbs sampling. Proceedings of the 3rd international workshop on distributed statistical computing: Vienna. p 125.

Poole KG, Porter AD, de Vries A, Maundrell C, Grindal SD, and St. Clair CC. 2004. Suitability of a young deciduous-dominated forest for American marten and the effects of forest removal. Canadian Journal of Zoology 82:423-435.

Powell RA. 1994. Structure and spacing of Martes populations. In: Buskirk SW, Harestad AS, Raphael MG, and Powell RA, eds. Martens, sables, and fishers: biology and conservation. Ithaca, New York, USA: Cornell University Press, 101-121. 
468 R Core Team. 2013. 2.15 ed. R: A language and environment for statistical computing. R

$469 \quad$ Foundation for Statistical Computing, Vienna, Austria.

470 Robitaille J-F. 2017. Morphology, diet, and physical condition of American martens, fishers, and 471 wolverines in Canada. In: Zalewski A, Wierzbowska I, Aubry KB, Birks JDS, O’Mahony DT, and Proulx G, eds. The Martes Complex in the 21st century: ecology and conservation. Białowieża, Poland: Mammal Research Institute, Polish Acadamy of Sciences, 25-60.

Royle JA, Chandler RB, Sollmann R, and Gardner B. 2013. Spatial capture-recapture. Waltham, Massachusetts, USA: Academic Press.

Royle JA, and Dorazio RM. 2008. Hierarchical modeling and inference in ecology: the analysis of data from populations, metapopulations and communities: Academic Press.

Royle JA, and Young KV. 2008. A hierarchical model for spatial capture-recapture data. Ecology 89:2281-2289.

481 Simberloff D. 1987. The spotted owl fracas: mixing academic, applied, and political ecology. Ecology 68:766-772. 10.2307/1938346

483

484

485

486

487

488

Sirén AP, Pekins PJ, Abdu PL, and Ducey MJ. 2016. Identification and density estimation of American martens (Martes americana) using a novel camera-trap method. Diversity 8:3.

Skalski JR, Millspaugh JJ, and Ryding KE. 2008. Effects of asymptotic and maximum age estimates on calculated rates of population change. Ecological Modelling 212:528-535.

Slauson KM. 2015. Coastal Oregon and northern California populations of the Pacific marten (Martes caurina) species report. Arcata, CA, USA: U.S. Fish and Wildlife Service. p 143. 
489 Sollmann R, Mohamed A, Samejima H, and Wilting A. 2013. Risky business or simple solution

$490-$ relative abundance indices from camera-trapping. Biological Conservation 159:405-

491 412. http://dx.doi.org/10.1016/j.biocon.2012.12.025

492 Strickland MA, and Douglas RJ. 1987. Marten. In: Novak M, Baker JA, Obbard ME, and Malloch B, eds. Wild furbearers management and conservation in North America.

494 Toronto, Canada: Ontario Ministry of Natural Resources, 530-547.

495 Sun CC, Fuller AK, and Royle JA. 2014. Trap configuration and spacing influences parameter estimates in spatial capture-recapture models. PLoS ONE 9:e88025.

497 10.1371/journal.pone.0088025

Thompson ID, and Colgan PW. 1987. Numerical responses of martens to a food shortage in northcentral Ontario. The Journal of Wildlife Management 51:824-835.

US Fish Wildlife Service. 2015. Endangered and threatened wildlife and plants; 12-month finding on a petition to list Humboldt Marten as an endangered or threatened species.

Verts B, and Carraway LN. 1998. Martes americana (Turton). Land mammals of Oregon: University of California Press, 406-410.

Whittington J, Hebblewhite M, and Chandler RB. 2018. Generalized spatial mark-resight models with an application to grizzly bears. Journal of Applied Ecology 55:157-168.

Zielinski WJ. 2013. The forest carnviores: fisher and marten. In: Long J, Skinner C, North M, Winter P, Zielinski WJ, Hunsaker C, Collins B, Keane J, Lake F, Wright J, Moghaddas E, Jardine A, Hubbert K, Pope K, Bytnerowicz A, Fenn M, Busse M, Charnley S, Patterson T, Quinn-Davidson L, and Safford HD, eds. Science synthesis to support Forest 
512 Plan Revision in the Sierra Nevada and Southern Cascades. Albany, CA: U.S.

513 Department of Agriculture, Forest Service, Pacific Southwest Research Station 261-301.

514 Zielinski WJ, Slauson KM, Carroll CR, Kent CJ, and Kudrna DG. 2001. Status of American

515 martens in coastal forests of the Pacific states. Journal of Mammalogy 82:478-490.

516 


\section{Table Captions}

518 Table 1. Input values for a viability analysis of subpopulations of coastal Pacific martens (Martes

519 caurina) in the Oregon Dunes Recreation Area.

520 Table 2. Three estimates of maximum intrinsic growth rate (r) bracketing our uncertainty from

521 most to least conservative life history assumptions of annual survival for population viability

522 modeling of the coastal Pacific martens (Martes caurina) in our study area in the Oregon Dunes

523 Recreation Area.

524 Table 3. Summary statistics from a spatial mark-resight model with telemetry data that estimated

525 the density of coastal Pacific martens (Martes caurina) in our study area in the Oregon Dunes

526 Recreation Area from Oct. 2015 to Jan. 2016. Significant effects (parameters with 95\% CRI's

527 not-overlapping 0), not including estimates of density, abundance, sigma, or intercepts, are 528 indicated in bold. 


\section{Figure captions}

534 Figure 1. We collected location data on coastal Pacific martens (Martes caurina) in the Oregon

535 Dunes Recreation Area, west of Highway 101, Oct. 2015 to Jan. 2016. The study area is bounded

536 to the north and south by the Siuslaw and Coos Rivers, respectively, and divided by the Umpqua

537 River in the center, which is approximately $600 \mathrm{~m}$ wide where it meets the Pacific Ocean. This

538 area had extensive fragmentation during our study with vegetated islands surrounded by open

539 sand. Imagery sources: Esri, DigitalGlobe, GeoEye, Earthstar Geographics, CNES/Airbus DS,

540 USDA, USGS, AeroGRID, IGN, and the GIS User Community.

541 Figure 2. Examples of uniquely marked individual martens (Martes caurina). (a) A female

542 marten with GPS collar sniffing strawberry jam. (b) A male marten with unique GPS collar with

543 two antennas. (c) A female marten with three reflective bands. (d) A male marten with two

544 reflective bands (middle, end of antenna). We reviewed photographic clusters where the same

545 individual was present in consecutive photos, and we identified individual martens for the spatial

546 mark-resight analysis. We discarded photographic clusters if we were unable to distinguish

547 whether a marten was marked or unmarked ( $<1 \%$ of all photos collected).

548 Figure 3. Technical articles that included the keywords "marten", "density", "territory", and

549 "home range". Of the $>75$ papers reviewed for North American martens (Martes americana, $M$.

550 caurina), four reported both home range sizes and density. Home ranges were estimated using

551 either 100\% Minimum Convex Polygons (MCP) or time-influenced Local Convex Hulls (t-

$552 \mathrm{LoCoH}$ ). Reported densities were either minimum known alive (MNKA) or calculated with

553 spatial mark-resight. Mean and 95\% confidence intervals reported if available in the study. Other

554 studies were conducted in Maine, USA which included estimates from three study areas (Payer 
555 \& Harrison 1999), central British Columbia, Canada (Poole et al. 2004), New Hampshire, USA

556 (Sirén et al. 2016), and Quebec, Canada (Godbout \& Ouellet 2010).

557 Figure 4. We conducted a spatial mark-resight study using remotely triggered cameras and by

558 marking the coastal Pacific marten (Martes caurina) with unique reflective strips on their collars

559 (Fig. 2) in the northern portion of the coastal Oregon Dunes Recreation Area from 4 December

5602015 to 12 January 2016. Here, we show the a) location of all camera stations, b) stations which

561 detected female martens, c) stations which detected male martens, and unmarked martens (large

562 black dots). For (b) and (c), individual martens are depicted by unique colored dots (camera

563 station detections), and outlines (outer boundary of territories). Imagery sources: Esri,

564 DigitalGlobe, GeoEye, Earthstar Geographics, CNES/Airbus DS, USDA, USGS, AeroGRID,

565 IGN, and the GIS User Community.

566 Figure 5. One-thousand density-dependent stochastic population projections (gray) for coastal

567 Pacific marten (Martes caurina) from the theta-logistic model, assuming a linear relationship

568 between per-capita population growth and population size $\left(\hat{\mathrm{I}}_{s}=1\right)$ beginning at three values of

569 carrying capacity $(\mathrm{K} ; 20,30$, or 40$)$, and three human-caused mortalities averaging 1,2 , or three

570 marten annually. The mean population trajectory is given by the black line, and the red line

571 signifies the pseudo-extinction threshold of 2 individuals. The proportion of trajectories falling

572 below this threshold is the probability of extirpation $\operatorname{Pr}(\mathrm{ext})$. Stochastic mortalities averaging two

573 or more marten lead to substantial extirpation risk within the next 40 years, particularly for

574 smaller values of $\mathrm{K}$.

575 Figure 6. One-thousand density-dependent stochastic population projections (gray) for a coastal

576 Pacific marten (Martes caurina) from the theta-logistic model assuming a convex relationship

577 between per-capita population growth and population size $\left(\hat{I}_{s}=2\right)$ beginning at three values of 
578 carrying capacity $(\mathrm{K} ; 20,30$, or 40$)$, and three human-caused mortalities averaging 1,2 , or three

579 marten annually. A $\hat{I}_{s}>1$ may be more realistic for long-lived mammals, because the onset of

580 density dependence likely occurs at higher population densities once crowding of home ranges

581 occurs; assuming values where $\hat{I}_{s}>1$ is less conservative because the population will be more

582 permissive to mortality or other mortality. The mean population trajectory is given by the black

583 line, and the red line signifies the pseudo-extinction threshold of two individuals. The proportion

584 of trajectories falling below this threshold is the probability of extirpation $\operatorname{Pr}(\mathrm{ext})$. Within the

585 next 40 years, stochastic mortalities averaging two or more marten lead to substantial extirpation

586 risk, particularly for smaller values of $\mathrm{K}$.

587 


\section{Table $\mathbf{1}$ (on next page)}

Input values for coastal marten viability analysis.

Input values for coastal Pacific marten (Martes caurina humboldtensis) viability analysis in the Oregon Dunes Recreation Area. 
Table 1. Input values for coastal Pacific marten (Martes caurina humboldtensis) viability analysis in the Oregon Dunes Recreation Area.

\begin{tabular}{lcl}
\hline Variable & Value & \\
\hline Age at first parturition & 2 & Mead (1994) \\
Average number of kits/year $(m)$ & 1.5 & Aune \& Schladweiler (1997), Flynn \& Schumacher $(2016)^{\mathrm{a}}$ \\
Survivorship to first parturition & & \\
& 0.35 & \\
$(l a)$ & & \\
Kit survival (age 0-1) & 0.49 & Johnson et al. (2009) \\
Yearling survival (age 1-2) & 0.7 & Average for North American martens, McCann et al. (2010) \\
Range of adult survival (age 2+) & $0.7-0.9$ & McCann et al. (2010) \\
\hline
\end{tabular}

${ }^{a}$ We choose $\mathrm{m}=1.5$ assuming 3 offspring and a $50 \%$ sex ratio as reasonable as among the highest observed litter size that would be expected to be achieved at low population density. For instance, Strickland \& Douglas (1987) reported that both pregnancy rates and numbers of corpora lutea in pregnant female martens in Ontario were stable, ranging from $91-100 \%$ and 3.19-3.53, respectively. Aune \& Schladweiler (1997) reported pregnancy rates similar for 2 populations in Montana, ranging from 76-95\% over 5 years, but a lower mean number of corpora (2.6) per adult female in the southwestern part of the state leading to an estimate of $m=1.1$. Thompson $\&$ Colgan (1987) reported 2.74-3.46 corpora lutea in pregnant females. Flynn and Schumaker (2016) observed pregnancy rates of martens in Southeast Alaska averaging only 47\% over seven years while litter size was 3.3 , producing an estimate of $\mathrm{m}=0.78$.

Aune KE, and Schladweiler P. 1997. Age, sex structure, and fecundity of the American marten in Montana. In: Proulx G, Bryant HN, and Woodard PM, eds. Martes: taxonomy, ecology, techniques, and management. Edmonton, Alberta, Canada: Provincial Museum of Alberta, 6177.

Flynn RW, and Schumacher TV. 2016. Habitat selection of American martens on northeast Chichagof Island, southeast Alaska, 1991-1997. Juneau, Alaska, USA. Wildlife Research Report ADF\&G/DWC/WRR-2016-6: Alaska Department of Fish and Game. p 25. 
Johnson CA, Fryxell JM, Thompson ID, and Baker JA. 2009. Mortality risk increases with natal dispersal distance in American martens. Proceedings of the Royal Society 276:3361-3367.

McCann NP, Zollner PA, and Gilbert JH. 2010. Survival of adult martens in northern Wisconsin. Journal of Wildlife Management 74:1502-1507. 10.2193/2009-297

Mead RA. 1994. Reproduction in Martes. In: Buskirk SW, Harestad AS, Raphael MG, and Powell RA, eds. Martens, sables, and fishers: biology and conservation. Ithaca, New York: Cornell University Press, 404-422.

Strickland MA, and Douglas RJ. 1987. Marten. In: Novak M, Baker JA, Obbard ME, and Malloch B, eds. Wild furbearers management and conservation in North America. Toronto, Canada: Ontario Ministry of Natural Resources, 530-547.

Thompson ID, and Colgan PW. 1987. Numerical responses of martens to a food shortage in northcentral Ontario. The Journal of Wildlife Management 51:824-835. 


\section{Table 2 (on next page)}

Bracketing uncertainty with three maximum intrinsic growth rates ( $r$ ).

Three estimates of maximum intrinsic growth rate $(r)$ bracketing our uncertainty from most to least conservative life history assumptions of annual survival for population viability modeling. 
Table 2. Three estimates of maximum intrinsic growth rate (r) bracketing our uncertainty from most to least conservative life history assumptions of annual survival for population viability modeling.

\begin{tabular}{ccccc}
\hline Annual & Female & Age of first & Survivorship & Maximum \\
Survival & kits per & parturition & to age at first & intrinsic \\
$\left(e^{-M}\right)$ & year & $(a)$ & parturition & growth rate \\
& $(m)$ & & $\left(l_{a}\right)$ & $(r)$ \\
\hline 0.7 & 1.5 & 2 & 0.35 & 0.143 \\
0.8 & 1.5 & 2 & 0.35 & 0.205 \\
0.9 & 1.5 & 2 & 0.35 & 0.268 \\
\hline
\end{tabular}




\section{Table 3 (on next page)}

Summary statistics of marten population density and detection rates using a spatial mark-resight (SMR) model.

Summary statistics from a spatial mark-resight model with telemetry data that estimated the density of the Humboldt subspecies of Pacific martens (Martes caurina humboldtensis) in our study area in the Oregon Dunes Recreation Area from Oct. 2015 to Jan. 2016. Significant effects (parameters with 95\% CRI's not-overlapping 0), not including estimates of density, abundance, sigma, or intercepts, are indicated in bold. 
Table 3. Summary statistics from a spatial mark-resight model with telemetry data that estimated the density of the Humboldt subspecies of Pacific martens (Martes caurina humboldtensis) in our study area in the Oregon Dunes Recreation Area from Oct. 2015 to Jan. 2016. Significant effects (parameters with 95\% CRI's not-overlapping 0), not including estimates of density, abundance, sigma, or intercepts, are indicated in bold.

\begin{tabular}{|c|c|c|c|c|}
\hline \multirow{2}{*}{ Parameter } & \multirow{2}{*}{ Mean (SD) } & \multicolumn{3}{|c|}{ Credible Interval } \\
\hline & & 2.5 & 50 & 97.5 \\
\hline Density $\left(\text { per } \mathrm{km}^{2}\right)^{\mathrm{a}}$ & $1.13(0.15)$ & 0.81 & 1.15 & 1.39 \\
\hline Abundance (\# martens) ${ }^{\mathrm{a}}$ & $9.75(1.32)$ & 7 & 10 & 12 \\
\hline$\alpha_{0}-$ habitat intercept & $-1.55(0.76)$ & -3.29 & -1.45 & -0.38 \\
\hline$\alpha_{1}-$ effect of forest cover & $1.07(0.53)$ & 0.17 & 1.02 & 2.22 \\
\hline$\beta_{0}-$ capture probability intercept & $-1.91(0.53)$ & -2.98 & -1.9 & -0.94 \\
\hline$\beta_{1}-$ female effect on capture probability & $0.79(0.6)$ & -0.36 & 0.79 & 1.98 \\
\hline$\delta_{0}-$ resight probability intercept & $-1.26(0.17)$ & -1.59 & -1.26 & -0.92 \\
\hline$\delta_{1}-$ female effect on resight probability & $0.75(0.19)$ & 0.38 & 0.76 & 1.11 \\
\hline$\delta_{2}$ - days since baiting effect on resight probability & $-0.06(0.02)$ & -0.11 & -0.06 & -0.02 \\
\hline$\sigma_{\text {male }}(\mathrm{m})$ & $1141.22(45.27)$ & 1058.39 & 1139.46 & 1233.75 \\
\hline$\sigma_{\text {female }}(\mathrm{m})$ & $277.81(6.17)$ & 266.46 & 277.63 & 290.1 \\
\hline
\end{tabular}

${ }^{a}$ based on the habitat mask within our state-space 


\section{Figure 1}

Our study area of coastal Pacific martens in the Oregon Dunes Recreation Area.

We collected location data on coastal Pacific martens (Martes caurina) in the Oregon Dunes Recreation Area, west of Highway 101, Oct. 2015 to Jan. 2016. The study area was bounded to the north and south by the Siuslaw and Coos Rivers, respectively, and divided by the Umpqua River in the center, which is approximately $600 \mathrm{~m}$ wide where it meets the Pacific Ocean. This area has extensive fragmentation with vegetated islands surrounded by open sand. Imagery sources: Esri, DigitalGlobe, GeoEye, Earthstar Geographics, CNES/Airbus DS, USDA, USGS, AeroGRID, IGN, and the GIS User Community. 


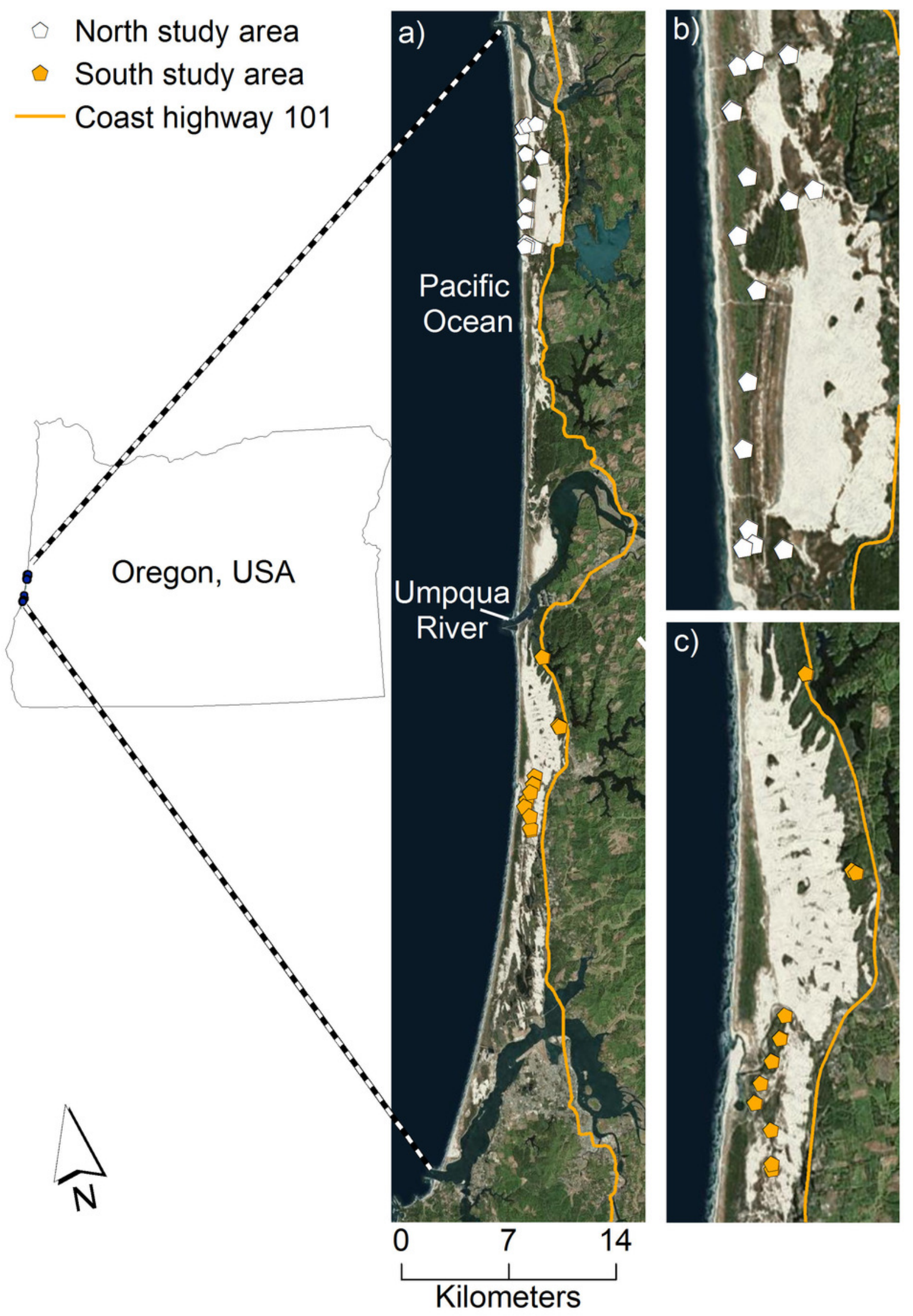




\section{Figure 2}

Photographs of uniquely marked martens

Examples of uniquely marked individual martens (Martes caurina). (a) A female marten with GPS collar sniffing strawberry jam. (b) A male marten with unique GPS collar with two antennas. (c) A female marten with three reflective bands. (d) A male marten with two reflective bands (middle, end of antenna). Each station included an olfactory lure (Gusto, Minnesota Trapline Products, Pennacock, MN) and baits that were checked and replaced weekly. We set remote cameras (Bushnell Aggressor, model: 119776; Bushnell Corporation, Overland Park, KS) two to three $\mathrm{m}$ from bait and we programmed them to record one photo after motion was detected with a one-second lag between consecutive photos. We reviewed photographic clusters where the same individual was present in consecutive photos, and we identified individual martens for the spatial mark-resight analysis. We discarded photographic clusters if we were unable to distinguish whether a marten was marked or unmarked $(<1 \%$ of all photos collected). 


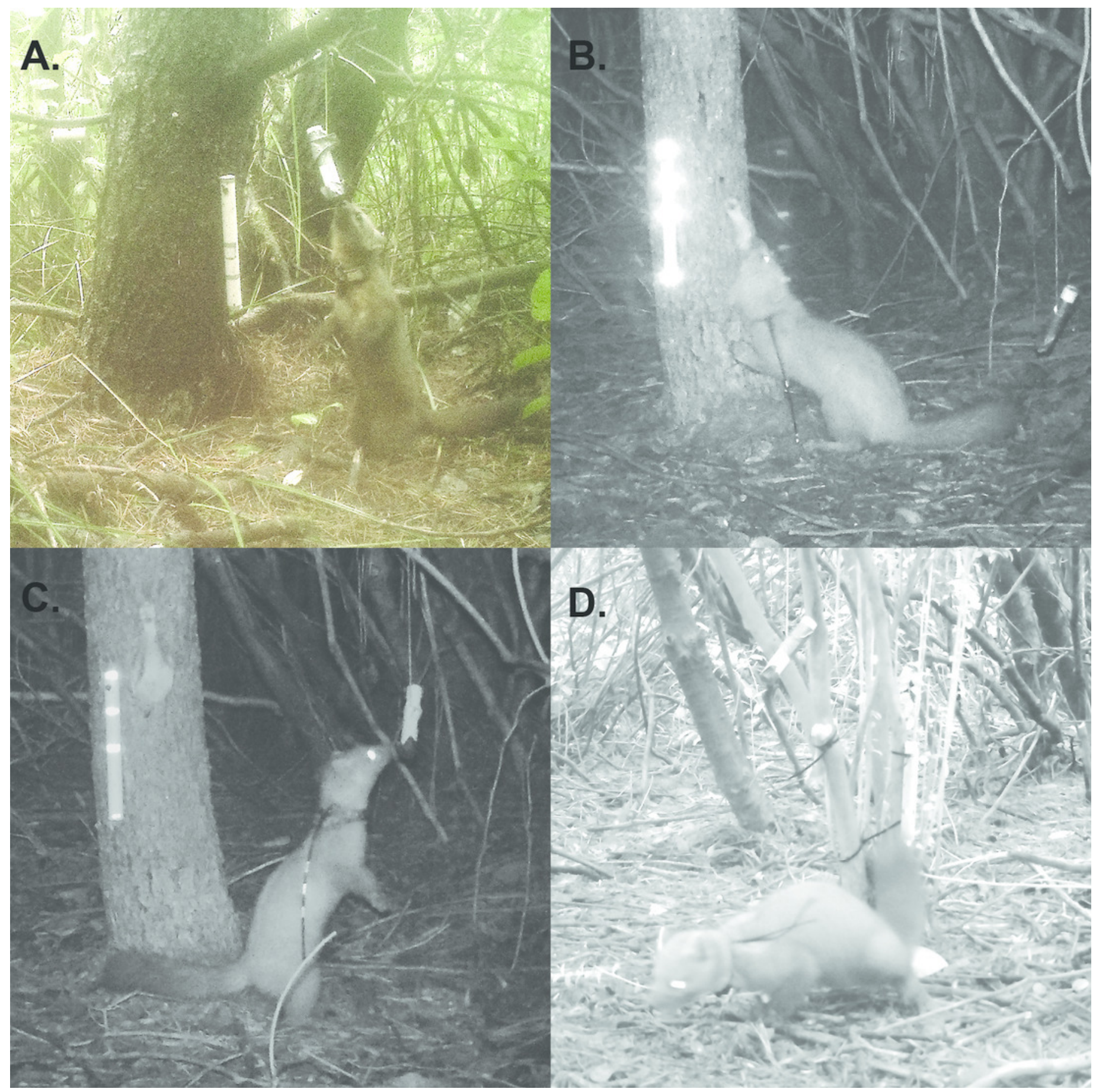




\section{Figure 3}

Density and home range size of North American martens

Technical articles that included the keywords "marten", "density", "territory", and "home range". Of the $>75$ papers reviewed for North American martens (Martes americana, $M$. caurina), four reported both home range sizes and density. Territories were estimated using either 100\% Minimum Convex Polygons (MCP) or time-influenced Local Convex Hulls (tLoCoH). Reported densities were either minimum known alive (MNKA) or calculated with spatial mark-resight. Mean and $95 \%$ confidence intervals reported if available in the study. Other studies were conducted in Maine, USA which included estimates from three study areas (Payer \& Harrison 1999), central British Columbia, Canada (Poole et al. 2004), New Hampshire, USA (Sirén et al. 2016), and Quebec, Canada (Godbout \& Ouellet 2010). 


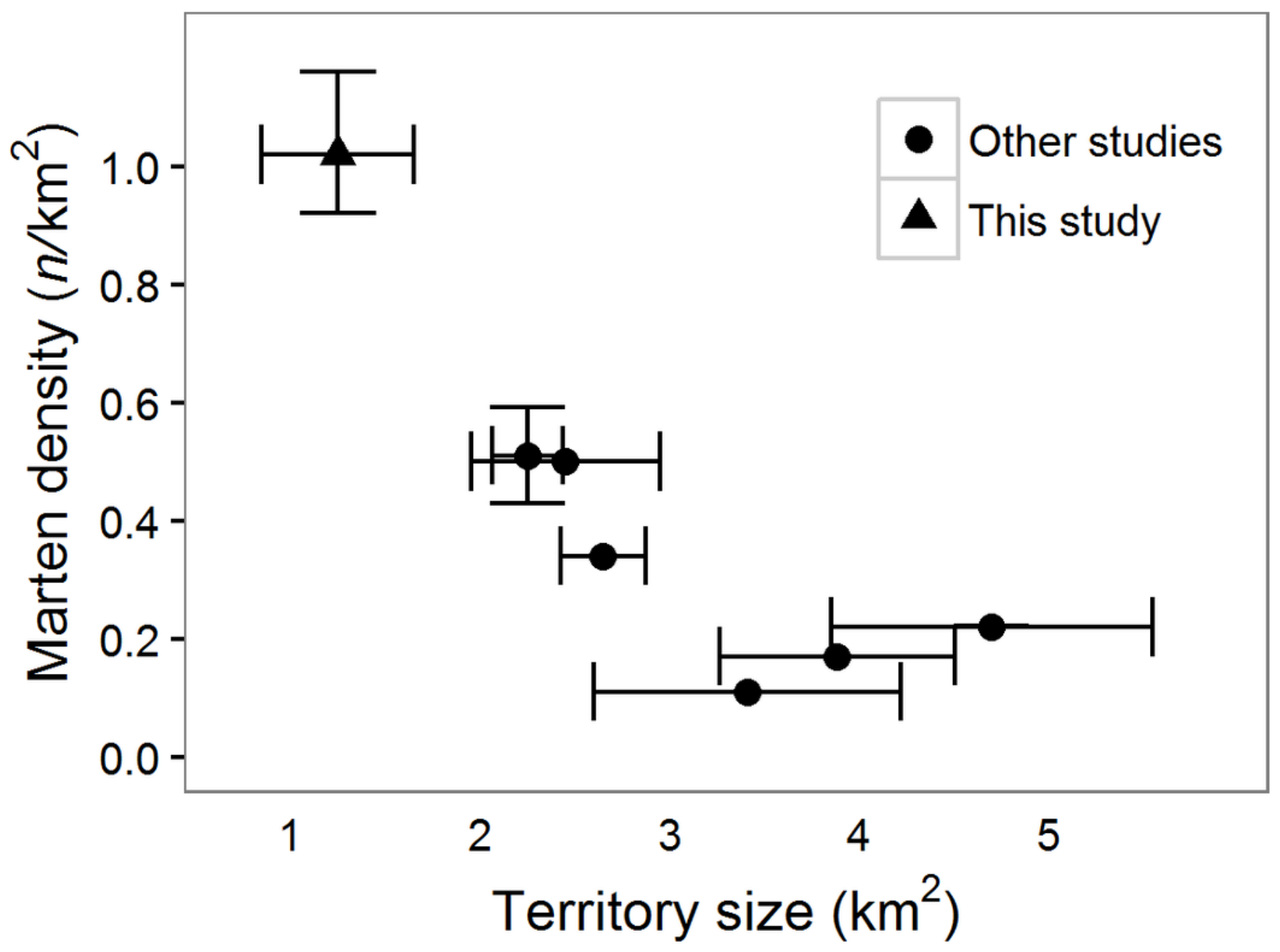




\section{Figure 4}

Our spatial mark-resight study area and coastal Pacific marten locations from remotely triggered cameras.

We conducted a spatial mark-resight study using remotely triggered cameras and by marking the coastal Pacific marten (Martes caurina) with unique reflective strips on their collars (Fig. 2) in the northern portion of the coastal Oregon Dunes Recreation Area from 4 December 2015 to 12 January 2016. Here, we show the a) location of all camera stations, b) stations which detected female martens, c) stations which detected male martens, and unmarked martens (large black dots). For (b) and (c), individual martens are depicted by unique colored dots (camera station detections), and outlines (outer boundary of territories). Imagery sources: Esri, DigitalGlobe, GeoEye, Earthstar Geographics, CNES/Airbus DS, USDA, USGS, AeroGRID, IGN, and the GIS User Community. 

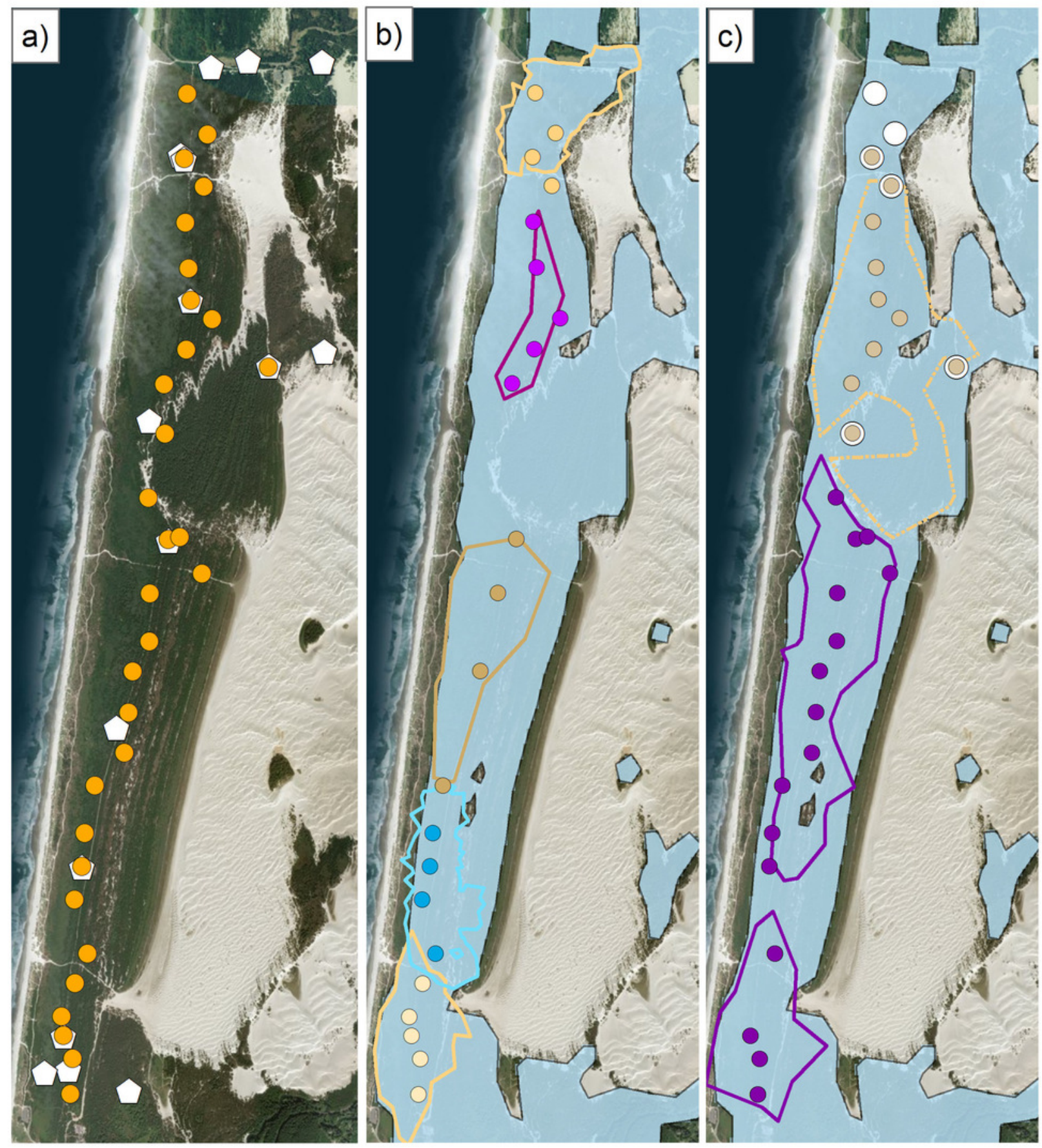

\section{$\triangle$ Trap locations}

$\square$ Vegetation cover (>40\%)

\section{- Camera stations}

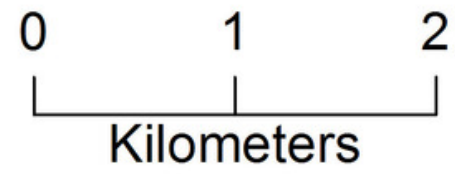




\section{Figure 5}

Marten population viability analysis, theta $=1$

One-thousand density-dependent stochastic population projections (gray) for coastal Pacific marten (Martes caurina) from the theta-logistic model, assuming a linear relationship between per-capita population growth and population size (theta $=1$ ) beginning at three values of carrying capacity $(K ; 20,30$, or 40$)$, and three human-caused mortalities averaging 1,2 , or three marten annually. The mean population trajectory is given by the black line, and the red line signifies the pseudo-extinction threshold of 2 individuals. The proportion of trajectories falling below this threshold is the probability of extirpation $\operatorname{Pr}($ ext). Stochastic mortalities averaging two or more marten lead to substantial extirpation risk within the next 40 years, particularly for smaller values of $\mathrm{K}$. 


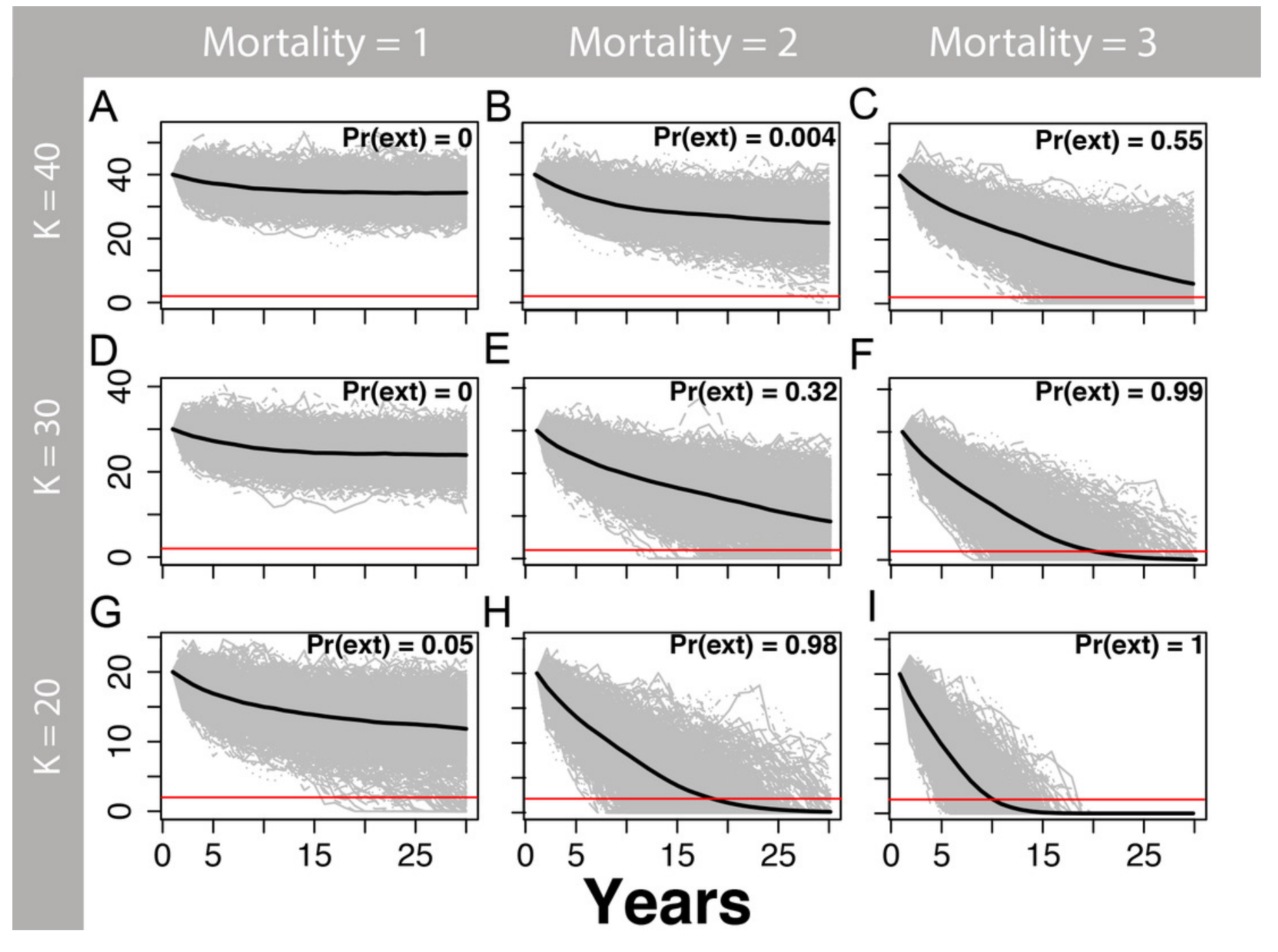




\section{Figure 6}

Marten population viability analysis, theta $=2$

One-thousand density-dependent stochastic population projections (gray) for a coastal Pacific marten (Martes caurina) from the theta-logistic model assuming a convex relationship between per-capita population growth and population (theta $=2$ ) beginning at three values of carrying capacity ( $K ; 20,30$, or 40 ), and three human-caused mortalities averaging 1 , 2 , or three marten annually. A theta $>1$ may be more realistic for long-lived mammals, because the onset of density dependence likely occurs at higher population densities once crowding of territories occurs; assuming values where theta $>1$ is less conservative because the population will be more permissive to mortality or other mortality. The mean population trajectory is given by the black line, and the red line signifies the pseudo-extinction threshold of two individuals. The proportion of trajectories falling below this threshold is the probability of extirpation Pr(ext). Within the next 40 years, stochastic mortalities averaging two or more marten lead to substantial extirpation risk, particularly for smaller values of $\mathrm{K}$. 


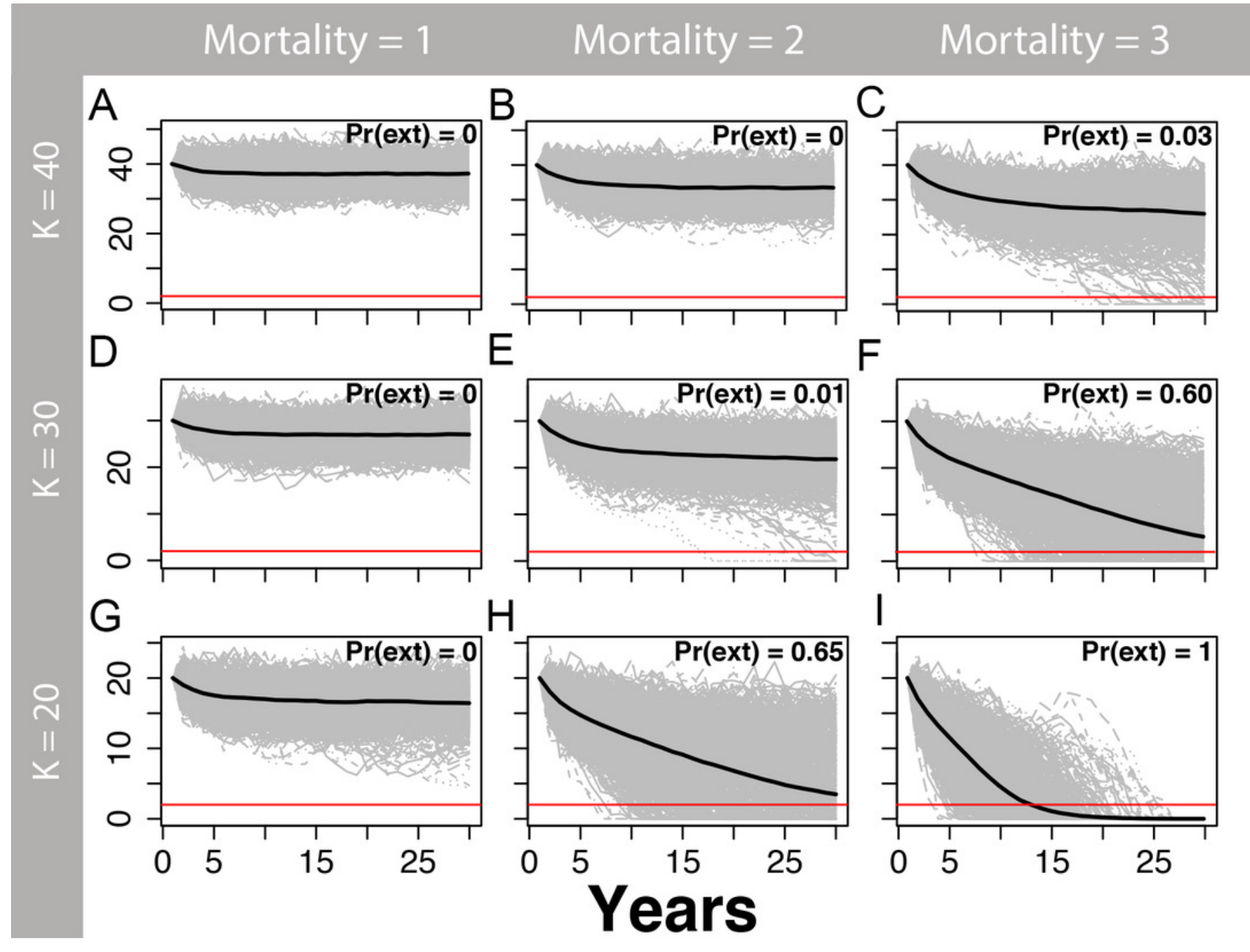

